\title{
A study on the structural optimization of bracing systems using ABAQUS
}

\section{Alexandre V. Silva*, Prof. Dr. Luiz C. M. V. Junior}

\begin{abstract}
This research aims to understand optimal bracing system location used in steel moment resisting frames under earthquake excitation. Bracing systems are used to increase a structure's stability but the number of braces also increases the costs of a structural design. Therefore, a low-rise building is modeled in the software ABAQUS in order to determinate the optimal configuration of its bracing system. Several bracing configurations were studied; when comparing two cases we concluded that it is possible to reduce the number of braces and lateral displacement by placing the bracing system in an optimal position. Further research shall be carried out to determine an optimal bracing configuration for different number of braces allowed and different bracing technologies.
\end{abstract}

\section{Key words:}

Structural optimization, steel frame, Abaqus.

\section{Introduction}

There is a variety of aspects that determine the viability of a structural design, such as costs and environmental impact. By using optimization techniques, the costs of a structural design can be significantly reduced since less material is required. Therefore, optimization is a tool that allows us to reduce natural resource consumption and thus contribute to sustainable initiatives.

In this context, the present research aims to understand how one reduces costs and simultaneously improves the serviceability and safety of a structure.

\section{Results and Discussion}

A planar-braced steel frame was modeled in ABAQUS to represent a 4-storey building. The bracing configuration adopted is the inverted V-bracing (chevron bracing). The bays have height of $3 \mathrm{~m}$ and span of $5 \mathrm{~m}$. Uniformly distributed loads are applied on the beams.

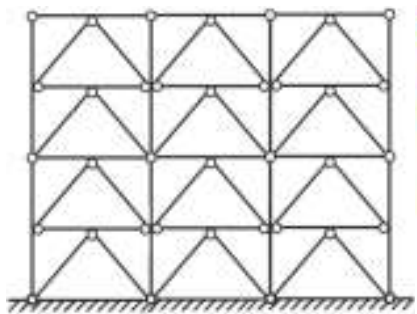

(a)

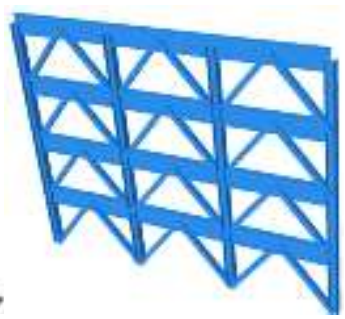

(b)
Image 1. Frame: (a) idealization, (b) model in ABAQUS

The seismic analyses were performed under the El Centro Earthquake (Image 2).

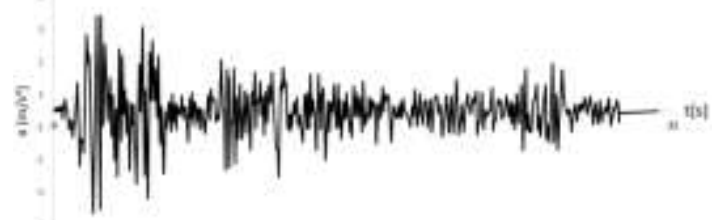

Image 2. El Centro Earthquake Accelerogram
In order to measure the effects of the bracing system, the horizontal displacement history of the right upper node is recorded.

Among the analyzed bracing configurations, two cases are presented in Image 3: (a) chevron braces removed from one bay, (b) chevron braces removed from two bays.

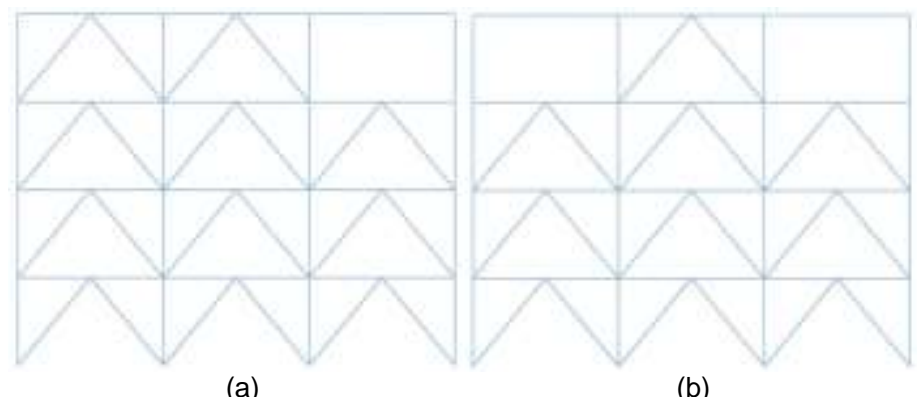

Image 3. Optimized bracing systems

In the cases (a) and (b), the optimization provided a slightly reduction in displacement $(1 \%$ and $8 \%$ respectively). Similarly, other cases also presented reduction in displacement.

\section{Conclusions}

Structural optimization is an important tool to determinate the optimal position of braces; it can lead to a reduction of the material consumption while it still guarantees the stability of a structural system.

\section{Acknowledgement}

Thanks to my advisor Prof. Luiz Vieira and to PIBIC/CNPq for all the support during this research.

${ }^{1}$ L. L. Beghini, "Building science through topology optimization", Ph.D. dissertation, University of Illinois at Urbana-Champaign, 2013.

2 Dassault Systèmes, Abaqus/standard user's manual (Version, 6,14), 2014 